\title{
Analytics on Antimicrobial Activity of Lichen Extract
}

\author{
Hitendra Yadav ${ }^{1}$, Sanjeeva Nayaka² and Manish Dwivedi ${ }^{1 *}$ (iD) \\ ${ }^{1}$ Amity Institute of Biotechnology, Amity University Uttar Pradesh, Gomtinagar Ext., Lucknow - 226028 , India. \\ ${ }^{2}$ Lichenology laboratory, CSIR- National Botanical Research Institute, Rana Pratap Marg, \\ Lucknow - 226 00, India.
}

\begin{abstract}
Lichen has a great medicinal value and represents the symbiotic relationship between fungi and algae or cyanobacteria. The genus Usnea longissima (Parmeliaceae), is a fruticose lichen with numerous biological activities like antimicrobial, antifungal and inhibitory activities for plant and human pathogens. Taxonomically it is well distinguished by pale greenish to yellowish-green colour and pendulous thallus with dense branches usually emerging from the main stem. Its fungal partner releases an extracellular compound called Usnic acid, a derivative of Dibenzofuran which is a naturally occurring secondary metabolite. In the present work, antimicrobial activities of Usnea longissimi are explored in various extraction solvents. The crude extracts were prepared in methanol, ethanol, ethyl acetate, acetone and different concentrations $(2.5,5,10,15,20 \mathrm{mg} / \mathrm{ml})$ followed by the determination of its antimicrobial activity against various microbes viz. Staphylococcus aureus, Escherichia coli, Pseudomonas aeruginosa and Fusarium oxysporum using agar well diffusion process. The maximum zone of inhibition was observed in the $15 \mathrm{mg} / \mathrm{ml}$ methanolic extract for Escherichia coli (34 mm), 10 $\mathrm{mg} / \mathrm{ml}$ methanolic extract for Staphylococcus aureus $(30 \mathrm{~mm}), 10 \mathrm{mg} / \mathrm{ml}$ ethyl acetate for Pseudomonas aeruginosa $(16 \mathrm{~mm})$ and $0.5 \mathrm{mg} / \mathrm{ml}$ ethanolic extract for Fusarium oxysporium $(14 \mathrm{~mm})$. Usnea longissimi have shown significant antibacterial and antifungal activity that encourage us to explore novel antimicrobial components within lichen biodiversity. These lichens further can be used as food supplements to cure various human diseases.
\end{abstract}

*Correspondence: mdwivedi@lko.amity.edu

(Received: January 01, 2021; accepted: April 24, 2021)

Citation: Yadav H, Nayak S, Dwivedi M. Analytics on Antimicrobial Activity of Lichen Extract. J Pure Appl Microbiol. 2021;15(2):701708. doi: 10.22207/JPAM.15.2.21

(C) The Author(s) 2021. Open Access. This article is distributed under the terms of the Creative Commons Attribution 4.0 International License which permits unrestricted use, sharing, distribution, and reproduction in any medium, provided you give appropriate credit to the original author(s) and the source, provide a link to the Creative Commons license, and indicate if changes were made. 


\section{INTRODUCTION}

Lichens produce the vast number of secondary metabolites with distinct biological properties $^{1,2}$. These metabolites from lichens including aliphatic and aromatic possesses low molecular weight comparatively ${ }^{3}$. These metabolites are complex, but predominantly small molecules, which comprise up to $20 \%$ of lichen's dry weight. Various types of components like amino acid derivatives, sugar alcohols, aliphatic acids, mucolytic lactones, monocyclic aromatic compounds, quinines, chromones, xanthones, dibenzofurans, depsides, depsidones, depsones, terpenoids, steroids, carotenoids, and diphenyl ethers are present in secondary metabolites of lichens. Mycobiont produces the secondary metabolites, and accumulate these compounds in the cortex (such as atranorin, parietin, usnic acid, fungal melanins) or the medullary layer (such as physodic acid, physodalic acid, protocetraric acid) in the form of extracellular tiny crystals on the outer surface of the hyphae. The secondary metabolism of the mycobiont also has some influence by the photobiont. Along with this, these lichens have also shown a significant role in estimating air pollution ${ }^{4}$.

Particular type of secondary metabolites is produced by using the appropriate composition of culture media with nutrients, sugars or polyols, $\mathrm{pH}$, temperature, light, stress etc.

Suitable culture conditions (such as nutrient medium, added sugars or polyols, $\mathrm{pH}$, temperature, light, stress) are required for the production of specific secondary metabolites. In many cases, lichen "tissue" cultures, can produce secondary substances, but the chemistry is different from the secondary metabolite of the corresponding natural lichen. Usnic acid is a natural lichen compound which is used in pharmaceutical preparation ${ }^{5}$. It is active against microorganisms and viruses as well as analgesics and antipyretics as well as useful in the treatment of hyperproliferative skin diseases, such as psoriasis as well as parasitic infestations. Pulvinic acid extracted from many lichens and fungi of higher groups represent bright yellow and orange pigments with antioxidant properties and boldine shows antioxidant activity, anti-inflammatory effects, as well as photoprotector capacity as a natural lichen metabolite ${ }^{6}$. Antibacterial and antifungal activity reported that some of the lichen metabolites such as atranorin, fumarprotocetraric acid, gyrophoric acid, lecanoric acid, physodic acid protocetraric acid, stictic acid and usnic acid showed relatively strong antimicrobial effects against six bacteria and ten fungi, among which were human, animal and plant pathogens, mycotoxin-producers and food spoilage organisms ${ }^{7}$. Plaudel has demonstrated ${ }^{8,9}$ the target-specific antibacterial activity of methanol extract against Gram-positive bacteria which were extracted from the five lichens belonging to Antarctica (Caloplaca regalis, Caloplaca spp, Ramalina terebrata, Stereocaulon alpinum) whereas usnic acid produced from lichens (south Spain) has good antibacterial activity against Gram-positive bacteria. Hirtusneanoside isolated from Usnea hirta showed growth inhibitory activities against Gram-positive bacteria. An investigation has ${ }^{10}$ reported that dichloromethane and methanol extracts of Proto usnea poeppigii possess strong antifungal effects against somefungal pathogens (Microsporum gypseum, Trichophyton mentagrophytes and $T$. rubrum) as well as against the yeasts Candida albicans, C. tropicalis, Saccharomyces cerevisiae and the filamentous fungi Aspergillus niger, $A$. flavus and A. fumigatus. Protousnea poeppigii contains metabolites like isodivaricatic acid, divaricatinic acid and usnic acid also showed antifungal activity against Microsporum gypseum, Trichophyton mentagrophytes and T. rubrum. Evernic and vulpinic acids causes the substantial inhibition of Ascospore germination of Sordaria fimicola, anthraquinone isolated from methanol extract of Caloplaca cerina has been reported to have significant antifunga ${ }^{11}$ activity and some of isolated bioactive compounds from Usnea longissimi showed its anti-inflammatory activity. Staphylococcus aureus was also found as an important cause of disease in human ${ }^{12,13}$.

Usnea longissimi and Cetrelia braunsiana are crucial members of Lichen family and proposed to have substantial antibacterial properties ${ }^{14}$ whereas Usnea longissimi was also found sensitive to air pollution. $U$. longissima belongs to rare type of lichens showing spore-producing structure.In India U. longissima is known to occur in Eastern Himalayas out of which 6 species were endemic to the region whereas Western Ghats in the southern part of 
the country represent the occurrence of 40 species out of which 11 species were endemic ${ }^{15}$. Cetrelia braunsiana shows the various characteristics that may include occurrence of laminalpseudocyphella, broad lobe and synthesis of aromatic substances, e.g., Orcinol-type depsides or depsidones. Previous researches have represented the impactful response of U.longissimi and Cetrelia braunsiana against some human diseases but still, its wide application in human health yet to be explored ${ }^{16,17}$ and more attention needs to be given to the exploration of biological activities of these two lichens. Therefore, the present work focused to investigate the antibacterial properties on Usnea longissimi and Cetrelia braunsiana. The findings may facilitate to utilize these lichens for human health.

\section{MATERIAL AND METHODS Lichen material}

The fresh lichen samples of Usnea longissima and Cetrelia braunsiana were given by Lichenology Laboratory of CSIR-National Botanical Research Institute (NBRI) which was collected previously from Himalaya.

\section{Chemical analysis of the lichen thallus}

TLC (Thin Layer Chromatography) is more accurate and very common technique for detecting and identifying lichen substances. The optimal condition has been developed in the laboratory of Culberson ${ }^{18}$ and isemployedas a standard procedure for TLC. The lichen substances were extracted in acetone and then loaded on merck silica gel $60 \mathrm{~F}_{254}$ plates and chromatogram was developed in standard solvent system(Taluene:Dioxane:Acetic acid - 180:60:8). The spots on the chromatography were visualized in normal light and short/long-wavelength ultraviolet (UV) light. Parmelinella wallichiana with the two common lichen substances salazinic acid (Rf class 2) and Atranorin (Rf class7) were used as the control for relating $R f$ values and $R f$ class of the unknown's substances.

\section{Extraction of Lichen Material}

Initially, the samples of Usnea longissimia and Cetrelia braunsiana were washed 5-6 times properly with tap water. Subsequent washing was done using distilled water and Polysorbate (Tween) 80 only once followed by frequent washing (4 times) with distilled water. Washing was done to minimize the contamination during the activation process. The washed sample was dried at room temperature (about $73-75^{\circ} \mathrm{F}$ ). After drying, about $200 \mathrm{gm}$ of the material was crushed using HL 1606 500-Watt Mixer Grinder. Five cycles were run to minimize the size of the sample particles.

The powdered lichen (10 gm) was wrapped in cylindrical pouch (size $8 \times 6 \mathrm{~cm}$ ) made up of grade-I Whatmann filter paper and kept inside the extractor arm of Soxhlet apparatus $^{19}$. A series of solvents as Methanol, Ethanol, Ethyl acetate and Acetone were used for extraction based on their polarity and for the each set of comprehensive extraction of secondary compounds, the process was conducted at the particular boiling temperature for $48 \mathrm{hrs}$.

After Soxhlet, the samples were evaporated using Rotary evaporation (Rotavap).

Preparation of Culture media for growth of microorganism

Nutrient agar plates were prepared by plating the media on petri dishes. Suspend 18.5 gm of nutrient agar powder in 1 litre of distilled water. All the components of culture media were thoroughly dissolved by heating and stirring. Further, sterilized culture media was poured intopetriplate.

PDA plates were prepared by using potato dextrose. Suspended 39.0 gm of potato dextrose agar powder in 1 litre of distilled water. To dissolve it, media was heated and autoclaved. Sterilized media was poured to prepare plates for culture.

\section{Microorganisms}

Total of five bacterial cultures (Pseudomonas aeruginosa, Agrobacterium tumefaciens, Escherichia coli, Streptococcus mutans and Staphylococcus aureus) and three fungal culture of Aspergillus niger, Candida albicans, Fusarium oxysporum were used in experimentations and screening process. All the cultures were obtained from the Pharmacological Laboratory, National Botanical Research Institute (NBRI), Lucknow. The cultures were stored at $4^{\circ} \mathrm{C}$ and for further analysis, concerned strains were revived from the same stock in solid and semisolid nutrient agar slants.

\section{Determination of Antimicrobial Activity}

Antimicrobial activity was investigated using a well-diffusion method ${ }^{20}$. The Nutrient Agar medium was transferred into one-fourth 
volume of Petri plates for antibacterial activity. Potato Dextrose Agar medium was transferred into one-fourth volume of Petri plates for antifungal activity. Inoculation of cultures $(100 \mathrm{mg} / \mathrm{ml})$ to this medium was carried out uniformly using glass spreader. Five wells were made in each Petri plate. Different concentration of crude extracts of Methanol, Ethanol, Ethyl acetate and Acetone (i.e. $2.5 \%, 5 \%, 10 \%, 15 \%$ and $20 \%$ ) were prepared as individual stock solutions by mixing Dimethyl Sulfoxide (DMSO) and Distilled Water. These stock solutions of different concentrations were filled in their respective wells along with DMSO as negative control and Streptomycin (in antibacterial testing) and Ketoconazole (in antifungal testing) as a positive control. The plates were labelled and incubated for 24 hrs at 37 degrees Celsius

\section{RESULTS AND DISCUSSION Chemical analysis of the lichen thallus}

Extracted components from the Lichen thallus was further identified by thin-layer chromatography and its analysis of the separated bands reveal the presence of various compounds present in lichen thallus. The occurrence of diverse compounds in the various extracts of Lichen thallus is demonstrated in Fig. 1 (Table 1). Each component present in extract illustrates the significant alteration in coloursafter it reacts with the spray reagent.

In TLC, Rf (retardation factor) value play a crucial role to quantify the movement of a components on a stationary phase e.g., silica plate with a suitable solvent system and that can be referred as the ratio of the distance covered by the component from its initial stage to the movement doneby the solvent from the origin point. In the case of Usnea longissimi, the resultant plate revealed the presence of usnic acids in natural thallus and evernic acid, barbatic acid, diffractaic acid, usnic acid in thallus extract. For Cetrelia braunsiana, natural thallus showed the alectoronic acid whereas thallus extract showed the presence of alectoronic acid and collatolic acid (Table 1).

Analysis of antimicrobial activity of lichens extract samples

We found that the Usnea longissimi and Cetrelia braunsiana extracts presented antimicrobial activity against most of the tested micro-organism. Zone diameters were found

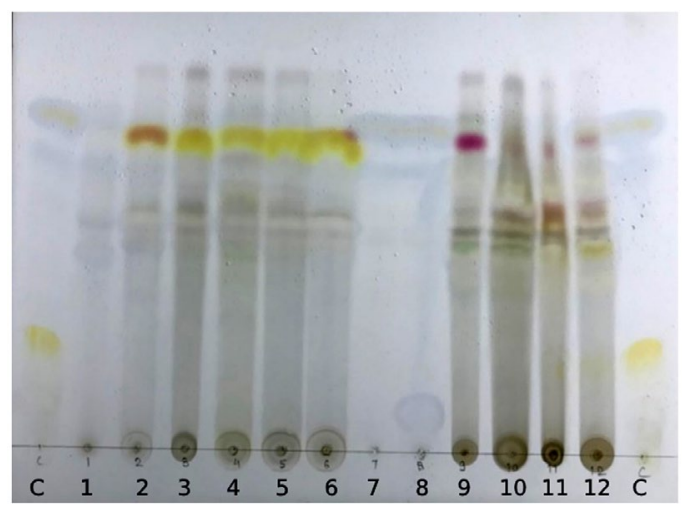

Fig. 1. Thin Layer Chromatography showing chemistry of Usnea longissima (1 \& 2 natural thallus, 3 ethanol, 4 methanol, 5 ethyl acetate, 6 acetone extract) and Cetrelia braunsiana ( 7 \& 8 natural thallus, 9 ethanol, 10 methanol, 11 ethyl acetate, 12 acetone extract

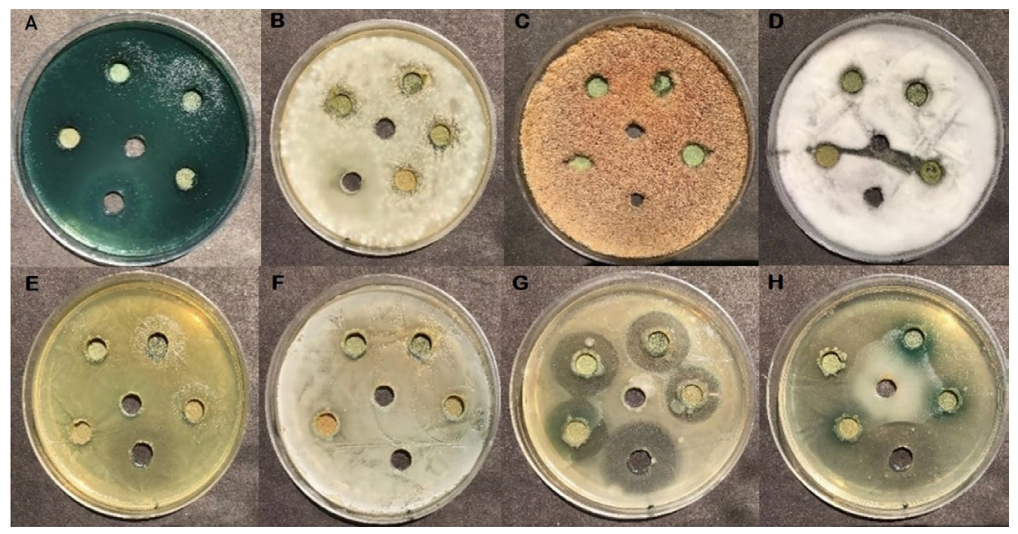

Fig. 2. Inhibition zone against the bacterial and fungal pathogen in $20 \mathrm{mg} / \mathrm{ml}$ concentration of Usnea longissimi. A) Pseudomonas aeruginosa B) Candida albicans C) Aspergillus niger D) Fusarium oxysporium E) Staphylococcus aureus F) Streptococcus mutans G) Escherichia coli H) Agrobacterium tumefaciens 


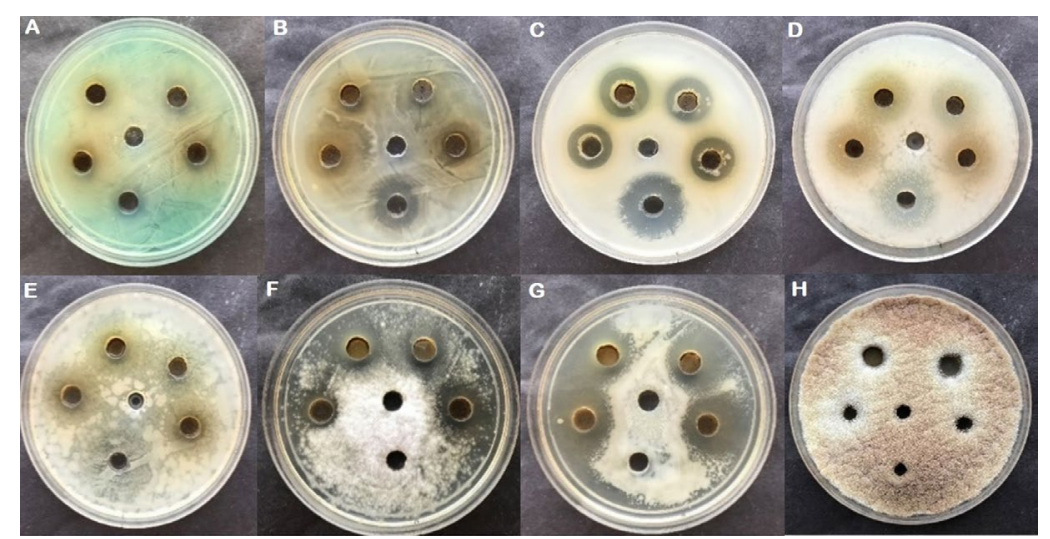

Fig. 3. Inhibition zone against bacterial and fungal pathogen in $15 \mathrm{mg} / \mathrm{ml}$ concentration of Cetrelia braunsiana. A) Pseudomonas aeruginosa B) Agrobacterium tumefaciens C) Escherichia coli D) Staphylococcus aureus E) Streptococcus mutans F) Fusarium oxysporium G) Candida albicans H) Aspergillus niger

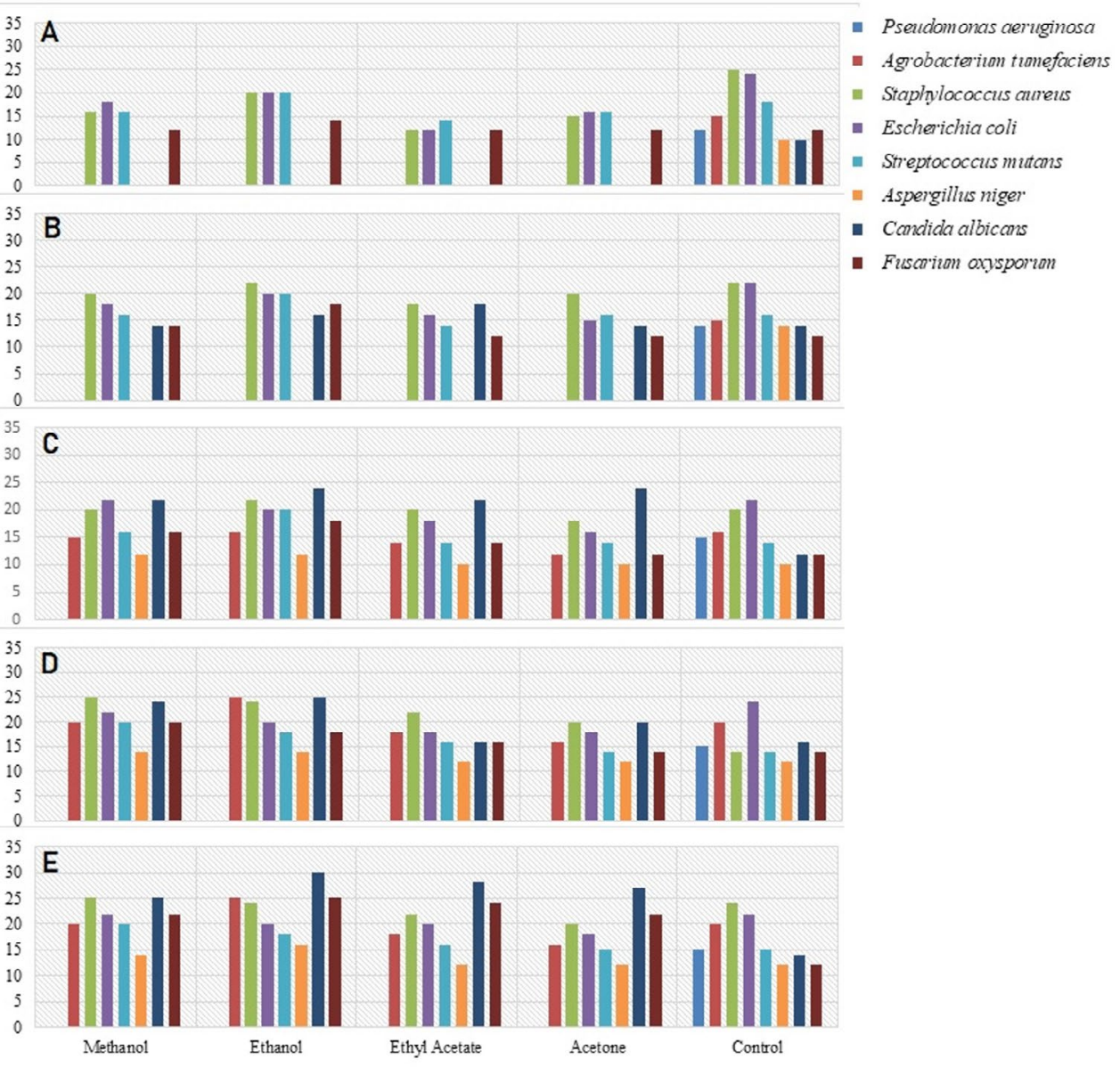

Fig. 4. Inhibitory zones recorded from the antimicrobial activity of extract from Cetrelia braunsiana: A) Inhibitory zone variations in $2.5 \mathrm{mg} / \mathrm{ml}$ extract. B) Inhibitory zone variations in $05 \mathrm{mg} / \mathrm{ml}$ extract. C) Inhibitory zone variations in $10 \mathrm{mg} / \mathrm{ml}$ extract. D) Inhibitory zone variations in $15 \mathrm{mg} / \mathrm{ml}$ extract. E) Inhibitory zone variations in $20 \mathrm{mg} / \mathrm{ml}$ extract (Table S2) 
varied for each extract of Usnea longissimi and Cetrelia braunsiana that shows the effectiveness and amount of present antimicrobial compounds in the extract. Different concentration $(2.5 \mathrm{mg} /$ $\mathrm{ml}, 5 \mathrm{mg} / \mathrm{ml}, 10 \mathrm{mg} / \mathrm{ml}, 15 \mathrm{mg} / \mathrm{ml}, 20 \mathrm{mg} / \mathrm{ml}$ ) of extracts from Usnea longissima and Cetralia braunsiana were employed as well as for the extraction different solvent were used namely, methanol, ethanol, ethyl acetate and acetone to get the best results against eight pathogens. The maximum inhibitory effect was recorded in the methanolic extract of Usnea longissima against $E$. Coli. However, the minimum inhibitory effect was observed in the acetone extract against Fusarium oxysporium (Figs. 2 \& 3)

After the analysis of the results, the methanolic extract of the Usnea longissima showed the largest inhibitory zone among the other extracts against the microbes of which their growth is inhibited. The ethanol, ethyl

Table 1. Present acid in natural thallus and extract thallus of Usnea longissimia and Cetrelia braunsiana

\begin{tabular}{lll}
\hline Lichen thallus & Natural thallus & Thids \\
& Usnic acid & Evernic acid, Barbatic acid, Diffractaic acid, Usnic acid \\
\hline $\begin{array}{l}\text { Usnea longissima } \\
\text { Cetrelia braunsiana }\end{array}$ & Alectoronic acid & Alectoronic acid, Collatolic acid \\
\hline
\end{tabular}

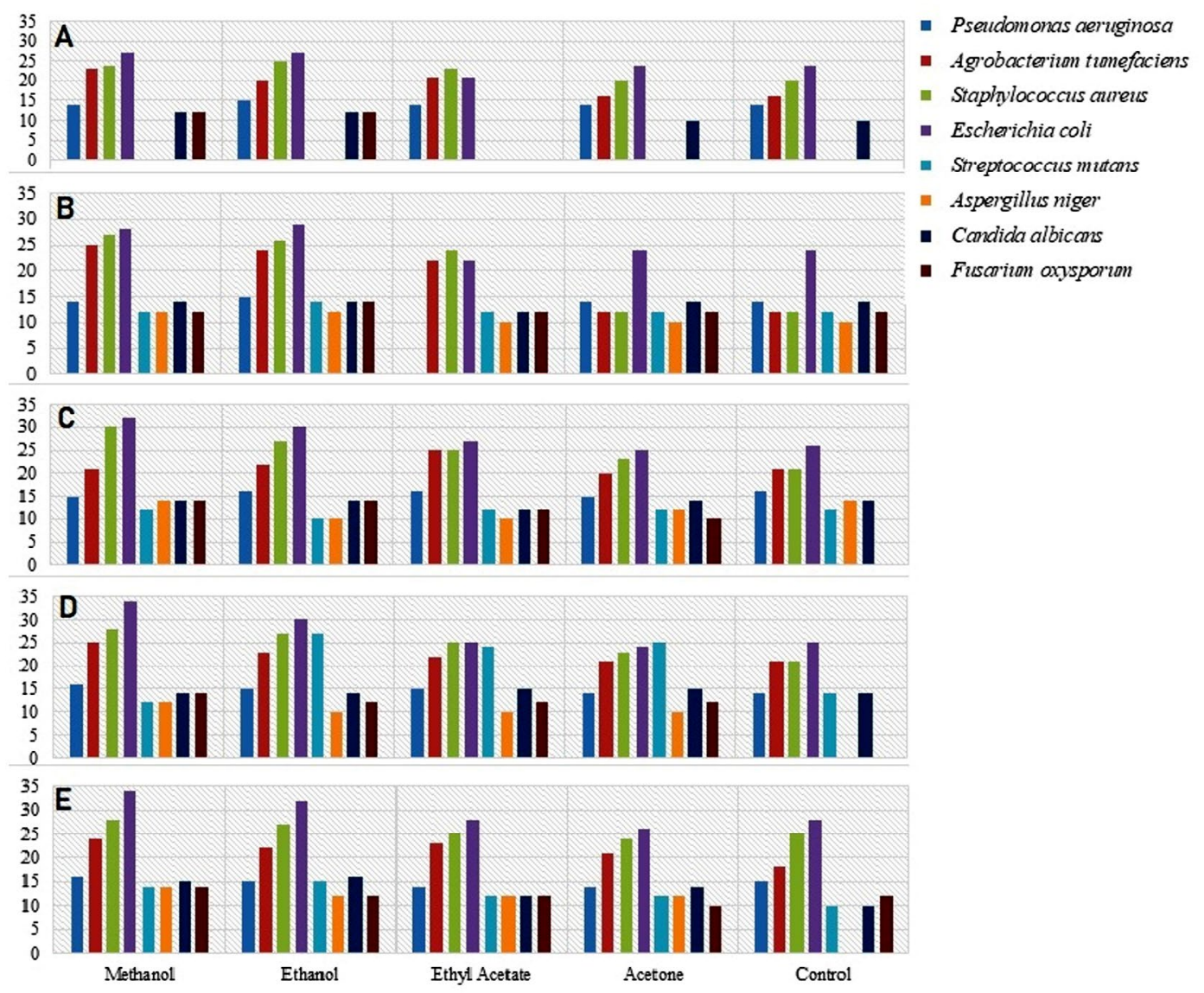

Fig. 5. Inhibitory zones recorded from the antimicrobial activity of extract from Usnea longissima: A) Inhibitory zone variations in $2.5 \mathrm{mg} / \mathrm{ml}$ extract. B) Inhibitory zone variations in $05 \mathrm{mg} / \mathrm{ml}$ extract. C) Inhibitory zone variations in $10 \mathrm{mg} / \mathrm{ml}$ extract. D) Inhibitory zone variations in $15 \mathrm{mg} / \mathrm{ml}$ extract. E) Inhibitory zone variations in $20 \mathrm{mg} / \mathrm{ml}$ extract (Table S1) 
acetate and acetone extracts were slightly less active compared to that of the methanol extract. For the methanol extract, the antimicrobial was detected at a concentration a $15 \mathrm{mg} / \mathrm{ml}$ against $E$. coli. Based on these results we may conclude that Methanol could be the more suitable solvent for the extraction than ethanol, ethyl acetate and acetone in case of $U$. longissima.

In present study methanolic extract of Usnea longissimi showed maximum inhibitory concentration with the concentration of $15 \mathrm{mg} /$ $\mathrm{ml}$ having inhibitory zone of $34 \mathrm{~mm}$ against $E$. coli [Table S1(iv) and Table S1(v)] whereas and minimum inhibitory concentration zone of $10 \mathrm{~mm}$ was shown by acetone extract against Fusarium oxiporum [Table S1(iii) and Table S1(v)]. In case of Cetrelia braunsiana, ethanolic extract showed maximum inhibitory concentration zone of $30 \mathrm{~mm}$ against Candida albicans having concentration of $20 \mathrm{mg} / \mathrm{ml}$ [Table S2(v)]. Aspergillus niger represents the minimum inhibitory zone of $12 \mathrm{~mm}$ by ethanolic extract of $C$. braunsiana [Table S2(iii), Table S2(iv), Table S2(v)].

Remarkably, no zone has been observed against Pseudomonas aeruginosa by thallus extracts of the lichens at the concentration of $2.5 \mathrm{mg} / \mathrm{ml}$ and $5 \mathrm{mg} / \mathrm{ml}$ in any of the solvents. [Table S1 and Table S2)] that indicates the effective concentration limit of the thallus extract against $P$. aeruginosa.

In the case of Cetralia braunsiana the maximum inhibitory effect was observed in the ethanolic extract (Fig. 4) against Candida albicans, while the minimum inhibitory effect was shown in the ethyl extract against Aspergillus niger.

These results clearly indicate that the lichen extract has strong potential to act as secondary metabolites in lichen which causes its antimicrobial activity (Fig. 5).

\section{CONCLUSION}

This investigation aims to explore the overall antimicrobial activity of thallus extracts of lichens, specifically Usnea longissima and Cetrelia braunsiana. After the studies, a certain correlation was established between the antimicrobial activity and the concentration of thallus extract in various solvents. In previous studies, some work has been done on antibacterial activity of lichen ${ }^{9}$ but still, further investigation needs to be done to implement novel properties of lichen towards human health and diseases. This study and outcomes on lichen have shed a light on its antimicrobial properties that indicate the need for lichens and its harvesting on large scale to benefit mankind. In this investigation, we found methanol and ethanol extract of Usnea longissima and Cetrelia braunsiana as a potent antimicrobial and antifungal agent. From the result obtained in the present study, it can be speculated that $U$. longissima and $C$. braunsiana have very broad antimicrobial activity with the ethanol and methanol extract. On the basis of results, it is suggested that the extracts of $U$. longissima and C.braunsiana can be used as a source of natural antimicrobial component for food supplement or in the medicinal or pharmaceutical industry. The study encourages to explore more to novel antimicrobial biomolecules within lichen biodiversity. Some of the bioactive phenolic compound from medicinal lichens have been characterized by researchers ${ }^{14}$ that shows its wide application in human welfare.

Another major aspect of lichen that showed the presence of secondary metabolites in its thallus which are responsible for their antimicrobial activity. But in my studies, the lichen species taken during this experiment did not show a strong inhibitory effect against pathogenic fungi. There could be some reason behind this property of lichen shown by its thallus extract as explained here. i) The acids present in these lichen species do not have any antimicrobial effect. ii) The acids present in these species do not properly get dissolved in acetone. 3) The secondary metabolites extract used in this experiment may be of weaker concentration and henceforth ineffective against a fungal pathogen. 4) The combination of acids present in lichen species is not effective with each other. Further investigations on the antimicrobial activity as well as the economical and efficient isolation process of the metabolite from the lichens are needed.

\section{SUPPLEMENTARY INFORMATION}

Supplementary information accompanies this article at https://doi.org/10.22207/JPAM.15.2.21

Additional file: Additional Table S1- S2. 


\section{ACKNOWLEDGMENTS}

MD would like to thank DST-INSPIRE Faculty award (2017), Government of India.

\section{CONFLICT OF INTEREST}

The authors declare that there is no conflict of interest.

\section{FUNDING}

None.

\section{AUTHORS' CONTRIBUTION}

SN and MD have conceptualized the work. $\mathrm{SN}$ has supervised the work. The formal analysis was done by $\mathrm{HY}, \mathrm{SN}$ and MD. Experiments were performed by $\mathrm{HY}$ and the manuscript was written by $\mathrm{HY}$ and MD.

\section{ETHICS STATEMENT}

Not applicable.

\section{DATA AVAILABILITY}

All datasets generated or analyzed during this study are included in the manuscript.

\section{REFERENCES}

1. Hale ME. The Biology of lichens. 1974; 3 edn Edward Arnold, London.

2. Joshi S, Upreti DK. Lichenometric studies in the vicinity of Pindari Glacier in Bageshwar district of Uttarakhand, India. Current Science. 2010;99, 231-235.

3. Turk AO, Yilmaz M, Kivanc M, Turk H. The antimicrobial activity of extracts of the lichen Cetraria aculeata and its protolichesterinic acid constituent. Zeitschrift für Naturforschung C. 2003;58c: 850 - 854. doi: 10.1515/ znc-2003-11-1219

4. Hawksworth DL, Rose F. Qualitative scale of estimating. Sulphur dioxide air pollution in England and Wales using epiphytic lichens. Nature. 1970;277 (5254): 145-148. doi: 10.1038/227145a0

5. Proksa B, Proksova A. Lichens metabolites. Usnic acid and its biological activity. Farm Obz. 1999;68: 139143.

6. O'Brien P, Carrasco-Pozo C, Speisky H. Boldine and its antioxidant or health-promoting properties, Chem. Biol. Interact, 2006;159(1):1-17. doi: 10.1016/j. cbi.2005.09.002

7. Rankovic' B, Mišic M. The antimicrobial activity of the lichen substances of the lichens Cladonia furcata, Ochrolechia androgyna, Parmelia caperata and Parmelia conspersa. Biotechnol Biotechnol Equip. 2008;22: 1013 -
1016. doi: $10.1080 / 13102818.2008 .10817601$

8. Bhattarai HD, Paudel B, Hong SG, Lee HK, Yim JH. Thin layer chromatography analysis of antioxidant constituents of lichens from Antarctica. J Nat Med. 2008; 62(4):481. doi: 10.1007/s11418-0080257-9

9. Paudel B, Bhattarai HD, Lee HK, Oh H, Shin HW, Yim $\mathrm{JH}$. Antibacterial activities of Ramalin, usnic acid and its three derivatives isolated from the Antarctic lichen Ramalina terebrata. Zeitschrift für Naturforschung C. 2010;65(1-2):34-38. doi: 10.1515/znc-2010-1206

10. Schmeda-Hirschmann G, Tapia A, Lima B, et al. new antifungal and antiprotozoal depside from the Andean lichen Proto usnea poeppigii. Phytother Res. 2008;22: 349 - 355. doi: 10.1002/ptr.2321

11. Manojlovic NT, Solujic S, Sukdolak S, Milosev M. Antifungal activity of Rubia tinctorum, Rhamnusfrangula and Caloplaca cerina. Fitoterapia. 2005;76(2):244-6 . doi: 10.1016/j.fitote.2004.12.002

12. Chambers HF. Community-associated MRSAresistance and virulence converge. N. Engl. J. Med. 2005;352(14):1485-1487. doi: 10.1056/ NEJMe058023

13. Rasigade JP, Vandenesch F. Staphylococcus aureus: a pathogen with still unresolved issues. Infect. Genet. Evol. 2014; 21:510-514. doi: 10.1016/j. meegid.2013.08.018

14. Choudhary MI, Asisuddin SJ, Rahman A. Bioactive phenolic compounds from a medicinal lichen, Usnea longissima. Phytochemistry. 2005;66: 2346-2350. doi: 10.1016/j.phytochem.2005.06.023

15. Singh KP, Sinha GP. Indian lichens: an annotated checklist. Botanical Survey of India, Kolkata 2010.

16. Buhl M, Peter S, Willmann M. Prevalence and risk factors associated with colonization and infection of extensively drug-resistant Pseudomonas aeruginosa: a systematic review. Expert Rev Anti Infect Ther. 2015;13(9):11591170. doi: $10.1586 / 14787210.2015 .1064310$

17. Gonçalves-de-Albuquerque CF, Silva AR, Burth P. Possible mechanisms of Pseudomonas aeruginosa-associated lung disease. Int J Med Microbiol. 2016;306(1):20-28. doi: 10.1016/j.jimm.2015.11.001

18. Culberson CF. Improved conditions and new data for the identification of lichen products by a standardized thin-layer chromatographic method. J Chromatogr. 1972;72(1):113-125. doi: 10.1016/00219673(72)80013-X

19. Balaji P, Bharath P, Satyan RS, Hariharan GN. In vitro antimicrobial activity of Roccella montagnei thallus extracts. Journal of Tropical Medicinal Plants, 2006; 7:2,169-173.

20. Bauer AW, Kirby WM, Sherris JC, Turck M. Antibiotic susceptibility testing by a standardized single disk method. Am J ClinPathol. 1966;45(4):493-496. doi: 10.1093/ajcp/45.4_ts.493 